\title{
Diálogos entre o ensino de ética e as questões éticas vivenciadas por Terapeutas Ocupacionais*
}

\author{
Dialogues between the teaching of ethics and \\ ethical issues faced by Occupational Therapists
}

\author{
Maria Angélica Pereira ${ }^{1}$, Maria Helena Morgani Almeida ${ }^{2}$
}

PEREIRA, M. A.; ALMEIDA, M. H. M. Diálogos entre o ensino de ética e as questões éticas vivenciadas por Terapeutas Ocupacionais. Rev. Ter. Ocup. Univ. São Paulo, v. 20, n. 2, p. 135 142, maio/ago. 2009.

RESUMO: Os profissionais que se ocupam do cuidar humano necessitam de uma formação que os auxilie na identificação de questões éticas e na produção de respostas. Objetivou-se contribuir para o aprimoramento do ensino de Ética em Terapia Ocupacional na USP-SP. Realizou-se estudo exploratório e descritivo. Foram obtidas informações de natureza qualitativa através de questionário não presencial de questões abertas, junto a docentes e egressos do Curso. As docentes informaram sobre conteúdos éticos de disciplinas sob sua responsabilidade e os egressos, sobre questões éticas com as quais têm se deparado e possíveis contribuições do Curso para a produção de respostas. Estabeleceu-se diálogo entre as informações obtidas. A disciplina de Ética Profissional e algumas outras disciplinas, especialmente as práticas, têm contribuído para uma formação ética. Os participantes apontam para a importância do ensino de ética ao longo da formação e da criação de espaços de interlocução. Nenhum participante citou a autonomia reduzida como questão ética. Os apontamentos dos participantes constituem-se como material a ser considerado para aprimoramento da formação ética do Terapeuta Ocupacional na USP.

PALAVRAS-CHAVE: Terapia ocupacional. Ética profissional. Ensino.

\footnotetext{
* Extraído de Relatório de Pesquisa apresentado ao Programa "Ensinar com Pesquisa" da Pró-Reitoria de Graduação da USP: FMUSP: Editais 2006 e 2008, intitulado: Diálogos entre o ensino de ética e as questões éticas vivenciadas por Terapeutas Ocupacionais. Autora: PEREIRA, M. A. Orientadora: ALMEIDA, M. H. M.: Disponível em: http://stoa.usp.br/mariato36/files/2030, e http://stoa.usp.br/mariato36/ files/2029.

1. Terapeuta Ocupacional pela USP, ex-bolsista do "Programa Ensinar com Pesquisa" da Pró-Reitoria de Graduação da USP. E-mail: mariato36@gmail.com

2. Professora Doutora do Departamento de Fisioterapia, Fonoaudiologia e Terapia Ocupacional da FMUSP. E-mail: hmorgani@usp.br Endereço para correspondência: Departamento de Fisioterapia, Fonoaudiologia e Terapia Ocupacional da FMUSP. Rua Cipotânea, 51. 05360-000. São Paulo, SP. E-mail: centroto@usp.br
} 


\section{INTRODUÇÃO}

$\mathrm{D}$ iante dos desafios cotidianos do cuidar, os profissionais necessitam de uma formação que os auxilie na resolução de uma ampla gama de questões éticas, seja na esfera da assistência, pesquisa ou ensino. Para abarcá-las a formação ética do Terapeuta Ocupacional na USP-SP, tem buscado abordar questões éticas específicas ou de aplicação concreta, a partir da articulação de temas de "Ética", "Bioética" e "Ética Profissional". Estes temas têm se constituído eixo teórico e conceitual da disciplina de Ética Profissional, em torno do qual se formulam questionamentos éticos sobre práticas profissionais vigentes (ALMEIDA; CASTIGLIONI, 2005).

A "Ética" enquanto ciência nos ajuda a refletir sobre a distinção entre o bem e o mal, a questão da consciência, do valor, da lei e dos ideais éticos de liberdade e justiça social (VASQUEZ, 2002; VALLS, 2006), e nos ampara para discutirmos sua aplicação às questões específicas e concretas como as da "Bioética" e da "Ética Profissional".

Segundo Segre e Cohen (1999) a "Bioética" refere-se à parte da ética que enfoca questões referentes à vida humana. De acordo com Potter (1971) ${ }^{1}$ citado por Diniz e Guilhem (2002) a Bioética é uma disciplina que visa promover uma vigilância ética ao desenvolvimento científico, para que não resulte em desrespeito aos valores humanos.

Segundo Garrafa (1995) a "Bioética" divide-se em Bioética Cotidiana, que engloba comportamentos e idéias de cada pessoa, fome, abandono, exclusão social, má distribuição de recursos, racismo; e Bioética das situaçõeslimite ou de fronteira que engloba temas decorrentes do desenvolvimento científico e tecnológico.

Pensar a "Ética Profissional" dos profissionais da saúde, inclusive do Terapeuta Ocupacional é pensar principalmente a ética aplicada à vida ou à "Bioética".

\section{Questões éticas em Terapia Ocupacional}

Lima $(2003,2006)$ expõe como um compromisso ético-político da Terapia Ocupacional refletir sobre o que tem motivado sua atuação, sobre como ela tem ressoado na população que atende e aponta que isso poderia evitar uma atuação perversa. Entendemos que a graduação possa auxiliar na antecipação e problematização de conteúdos éticos e, contribuir para a produção de futuras ações profissionais mais comprometidas com as reais necessidades da população.

Com o objetivo de aprimorar o ensino de Ética em Terapia Ocupacional na USP-SP, procuramos verificar se os Terapeutas Ocupacionais formados pela Instituição, nos moldes atuais, identificam desafios éticos na assistência, na pesquisa ou no ensino, se produzem respostas a estes desafios e se consideram que a formação profissional contribuiu para isto. Confrontamos essas informações a outras obtidas junto às docentes Terapeutas Ocupacionais, relativas aos conteúdos éticos oferecidos pelo Curso.

\section{PROCEDIMENTOS METODOLÓGICOS}

A pesquisa foi realizada em 2007 e 2008 e seguiu os padrões exigidos, tendo sido aprovada pelo Comitê de Ética em Pesquisa da FMUSP ${ }^{2}$. Realizamos pesquisa qualitativa, através de estudo exploratório e descritivo, com uso de questionário não presencial, de questões abertas. Ela foi precedida por um estudo piloto com o propósito de realizar ajustes aos questionários a serem empregados. Obtivemos informações junto a docentes Terapeutas Ocupacionais do Curso, e seus egressos.

Junto às docentes obtivemos informações relativas aos conteúdos éticos em disciplinas sob sua responsabilidade. E junto aos egressos coletamos e analisamos informações referentes às questões éticas atuais e possíveis contribuições do Curso para a produção de respostas. Por fim, estabelecemos diálogo entre estas informações.

Procedemos à análise temática de conteúdo das informações, adotando-se como eixo principal para análise, o tema "Ética".

\section{RESULTADOS E DISCUSSÃO}

Do total de 14 docentes do Curso, 3 foram excluídas da "população potencial participante da pesquisa": 2 por terem participado do estudo piloto e 1 por ser orientadora desta pesquisa. Quatro docentes não responderam ao questionário, participando de "fato" da pesquisa, 7 docentes.

Dos 66 potenciais participantes egressos, 38 (57,6\%) correspondiam aos critérios de inclusão, ou seja, cursaram a disciplina de Ética Profissional entre os anos 2004, 2005 ou 2006, atuavam há um ano ou mais, e residiam

1. POTTER, V. R. Bioethics: bridge to the future. Englewood Chiffs: Preventice Hall, 1971.

2. Projeto CAPPesq $n^{\circ} 0967 / 07$. 
ou trabalhavam no Estado de São Paulo. Destes, 2 (5,3\%) participaram do estudo piloto e $13(34,2 \%)$ se recusaram a participar. Constituiu-se de "fato" como população da pesquisa, 23 egressos $(60,5 \%)$.

\section{Diálogos entre o ensino de ética e as questões éticas vivenciadas por terapeutas ocupacionais}

Os resultados aqui apresentados referem-se a estudo realizado com docentes ${ }^{3} e$ egressos $^{4}$ através do Programa "Ensinar com Pesquisa" da Pró Reitoria de Graduação da USP, durante o período de 2007 e 2008.

Três docentes relatam o "desenvolvimento da eticidade na relação entre profissional e pessoa atendida" como conteúdo essencial em suas disciplinas.

Verificamos a importância deste tema também para os egressos, pois $82,6 \%$ apontam como resposta às questões éticas o uso da comunicação e negociação com equipe/ outros profissionais/sujeito/ família/ instituição/ sociedade.

Ainda, a responsabilização pelo sujeito tem sido um princípio adotado por $52,2 \%$ dos egressos para a produção de respostas às questões éticas vivenciadas. Segundo Franco et al. (1999) a responsabilização envolve ter em vista as pessoas e a defesa da vida, mobilizando todos os recursos que possam favorecer este objetivo.

Alguns dos egressos têm produzido como resposta a algumas das questões éticas o respeito à "autonomia" $\mathrm{da}$ pessoa. Dois egressos $(8,7 \%)$ referem estimular o sujeito a opinar sobre seu tratamento e $13 \%$ têm tratado informações sobre os sujeitos de forma a respeitar sua privacidade e ao mesmo tempo a autonomia do seu entorno.

Mas, como respeitar a privacidade da pessoa sem causar, em alguns casos, danos aos outros? Segundo Fortes (1998), "A privacidade é um conceito derivado da autonomia e engloba a intimidade, a vida privada, a honra e a imagem das pessoas (p. 73)". E, é a garantia da privacidade e da confidencialidade das informações que gera nos profissionais de saúde o dever ético e legal de manter o sigilo das informações.

As docentes não abordam diretamente a questão da autonomia, mas trazem temas estreitamente relacionados. Uma das docentes aborda a questão da relação de poder entre profissional e sujeito, e, outra docente, a questão da liberdade, necessidade e valor.

A questão ética que envolve como se posicionar frente a decisões que envolvem pessoas com autonomia reduzida não foi abordado explicitamente por nenhuma das populações, embora essa população seja comumente atendida pela Terapia Ocupacional.

Segundo Leopoldo e Silva $(1994)^{6}$, citado por Guimarães e Novaes (1999) os menores de idade e as pessoas com deficiência mental e não somente estes, são considerados nos códigos de ética e diretrizes de pesquisa como possuindo autonomia reduzida, ou seja, estão impossibilitados de fornecer consentimento após informação.

Quatro docentes relataram desenvolver a "alteridade 7 na relação profissional e pessoa atendida", sendo muitos os elementos citados: 2 citaram a importância da escuta cuidadosa; 3 , a abertura para o outro e o respeito às diferenças; 1 , a potencialização da vida; 1 , a potencialização da ação e do cuidado e 1 relatou a necessidade de transformação das relações de poder entre terapeuta e pessoa atendida.

Podemos inferir que as docentes citadas buscam contribuir para a formação de profissionais voltada para o cuidado humano e para a relação interpessoal através da alteridade, visto que há preocupação em formar profissionais que possam olhar a outra pessoa, preocupar-se com ela, responsabilizar-se e enxergá-la como sujeito (ZOBOLI, 2003).

Em consonância com o entendimento das docentes, $34,8 \%$ dos egressos referem à alteridade como uma possibilidade de resposta às questões éticas.

Sim, na prática, vamos percebendo que a grande resposta é se abrir ao encontro com o outro e ir compreendendo seus limites e ir apoiando-o nestas difíceis vivências.

Uma docente aponta para a contribuição da disciplina de Ética Profissional para a reflexão do estudante sobre as "relações institucionais", ou seja, sobre sua postura pessoal diante da diversidade de populações e instituições com as

3. Disponível em: http://stoa.usp.br/mariato36/files/2030, Acesso em 20 nov. de 2009.

4. Disponível em: http://stoa.usp.br/mariato36/files/2029, Acesso em 20 nov. de 2009.

5. Segundo Beauchamp e Childress (1985) autonomia é um termo derivado do grego autos (eu) e nomos (regra, governo, lei) e significa faculdade para governar a si mesmo.

6. LEOPOLDO e SILVA, F. et al. Ethical guidelines for FAPESP-sponsored research on human populations. Braz. J. Med. Biol.Res., v. 27, p. 2701-4, 1994.

7. Segundo Betto (2003), ter alteridade é ser capaz de apreender o outro na plenitude da sua dignidade, dos seus direitos e, sobretudo, da sua diferença. 
quais se depara durante o Curso.

Acreditamos que essa contribuição apontada pela docente tem se refletido na produção de respostas às questões éticas encontradas pelos egressos, pois $39,1 \%$ deles referem à busca por apoio institucional (equipe, gestor, órgãos representativos, governo) como resposta aos desafios éticos encontrados.

Da mesma forma, $13 \%$ dos egressos têm buscado alternativas éticas quando há falta de recursos na instituição para a realização da intervenção, seja a escolha de critérios quando a demanda é maior que a possibilidade de atenção, o que corresponde à diretriz ética da equidade; seja a exigência de melhores condições de trabalho, que se revela como uma importante reivindicação de direitos; ou mesmo priorizar as urgências individuais e do grupo.

Um dos egressos (4,3\%) deixa a sugestão de que sejam mais discutidas na graduação as possíveis questões éticas encontradas na relação do profissional com o serviço ou instituição.

A escassez de experiências interprofissionais na graduação foi apontada por um egresso $(4,3 \%)$ e não foram observados apontamentos referentes ao tema "relações interprofissionais" nas contribuições trazidas pelas docentes.

A opinião do egresso corrobora com as Diretrizes Curriculares dos Cursos de Terapia Ocupacional ${ }^{8}$, e com outras Diretrizes de Cursos da área da saúde, onde há a orientação de que a formação se volte para o trabalho em equipe e para a atenção integral à saúde (ALMEIDA et al., 2007).

Uma docente tem discutido a "posição do futuro profissional frente ao trabalho no contexto do SUS", entendida como uma questão ética. Um dos egressos $(4,3 \%)$ refere o tema quando sugere o aprofundamento do conhecimento das políticas sociais, com ênfase no SUS, SUAS e nas Políticas de Saúde Mental.

Pessini e Barchifontaine (2002) colocam que a questão dos recursos humanos é um dos desafios para implementação do SUS, visto que os profissionais e técnicos possuem qualificação precária e tem sido alvos de muitas reclamações.

Quanto a "Bioética das situações limite ou de fronteira", 1 docente relata que tem contribuído para a ocorrência de debates sobre:

(...) os limites de algumas situações clínicas e em situações polêmicas tais como a distinção entre princípios éticos e religiosos, a discussão dos direitos ao aborto, à eutanásia, à clonagem, ao experimento com animais (que recebem tratamentos diferenciados pelas diferentes sociedades $e$ países).

Situações que envolvam situações limites ou de fronteira não foram citados pelos egressos nem trazidos como questões éticas pelos mesmos, possivelmente por serem situações menos freqüentes na atuação do Terapeuta Ocupacional.

Quatro docentes citam elementos que envolvem a "bioética cotidiana", sendo eles: os compromissos éticos do profissional de saúde, o debate em torno das conseqüências sociais do avanço da tecnologia, o estigma que envolve a deficiência, o sigilo profissional, o cuidado com o fazer e a produção da pessoa atendida e as questões éticas presentes nos “(...) problemas que envolvem as populações tradicionalmente atendidas por Terapeutas Ocupacionais: exclusão social, violência, falta de oportunidades e acesso a direitos sociais, entre outros".

Os egressos, em consonância com a preocupação das docentes, elencaram muitas questões que se relacionam com a bioética cotidiana. Acreditamos que a parte das questões éticas elencadas, inclua-se também no âmbito da Ética Profissional e estejam relacionadas às múltiplas relações estabelecidas na atuação profissional - com a equipe, outros profissionais, sujeito, família, instituição e sociedade $(52,2 \%)$; sigilo profissional $(39,1 \%)$; dificuldade em realizar a intervenção $(30,4 \%)$; percepção de conduta inadequada da equipe $(30,4 \%)$; dificuldade em identificar os limites da autonomia $(21,7 \%)$; atuação quando não orientada pela alteridade $(17,4 \%)$; dificuldade na relação do sujeito/ profissional/ instituição/ sociedade com o prognóstico (13\%): ausência dos órgãos de classe $(4,3 \%)$; importância e relevância do tema "pesquisa" $(4,3 \%)$; quando pagamento do serviço realizado não é efetuado (4,3\%); institucionalização como possibilidade de alívio para o cuidador $(4,3 \%)$; problemas sociais do sujeito que restringem a ação profissional $(4,3 \%)$; o uso de estagiários substituindo profissionais $(4,3 \%)$.

O fim a que a Bioética se ocupa, ou seja, "defender a vida em seu sentido mais amplo possível" (PESSINI et al., 2002) tem sido um conteúdo tratado por 5 das 7 docentes participantes.

Lima (2006) aponta para a potencialização da vida, ou seja, para uma atuação que se faça além da manutenção

8. BRASIL. Parecer CNS/CES 6/2002. Diretrizes Curriculares nacionais do Curso de graduação em Terapia Ocupacional. Diário Oficial da União, 4 de mar. 2002. 
do corpo biológico, ou como traz Saraceno (1999) produza abertura de possibilidades para a pessoa e para seu entorno. Este tema é trazido também por um egresso $(4,3 \%)$ ao buscar promover qualidade de vida quando a cura/ reabilitação não são mais consideradas possibilidades de atenção.

A totalidade das docentes avalia que existe "contribuição do conjunto de disciplinas da graduação para a formação ética", identificam conteúdos relativos à ética em suas disciplinas, seja na forma de conteúdos previstos ou através do fomento de discussões e debates a partir de questionamentos éticos trazidos por estudantes.

Para os egressos, $30,4 \%$ referem que o Curso proporcionou uma formação ética, $4,3 \%$ entende que este oferece uma formação ampla e diversificada e 4,3\% que o mesmo fornece informações que são respaldo à ação futura. A formação crítica é apontada como proporcionada pelo Curso por $21,7 \%$ dos egressos.

A graduação em TO proporciona aos futuros profissionais a construção de uma visão e pensamento crítico, fundamentais para uma prática profissional que se aproxime de ideais éticos e para o crescimento e desenvolvimento da profissão.

A totalidade das docentes afirma a "contribuição da disciplina de Ética Profissional para o ensino de ética" no Curso. Duas docentes relatam que a disciplina contribui, pois

(...) além de fornecer subsidios para o aprofundamento da discussão, possibilita a troca de experiência entre os alunos que podem assim tomar contato com a complexidade das questões que se colocam para o profissional da saúde no contemporâneo, ajudando-os a deslocar-se de uma posição simplista e dicotômica.

(...) instiga o aluno a refletir sobre sua ação profissional cotidiana, bem como a sua postura pessoal diante de populações e instituições tão diversificadas com as quais se depara durante o Curso. Contribui para a compreensão e respeito das diferenças de valores, padrões de vida, preferências, regras sociais, saindo do lugar de saber do terapeuta, compreendendo e valorizando as trocas possiveis entre indivíduos, numa proposta de potencialização de forças e não de cisão entre poder e submissão.

Dessa forma, a disciplina de Ética Profissional, para as 2 docentes citadas tem a função de complementar os conteúdos abordados em outras disciplinas.

A idéia da disciplina como complementar para a formação ética das (os) futuros profissionais também é identificada por duas docentes do Curso, em um artigo de sua autoria:
(...) a disciplina de 'Ética Profissional' reúne e tem reforçado princípios éticos fomentados durante toda a formação, configurando-se como 'lócus' privilegiado para a consagração da relação entre o profissional e o outro como uma relação entre sujeitos (ALMEIDA; CASTIGLIONI, 2005).

Outra docente refere que a disciplina tem um papel de garantir que certos conteúdos éticos, caso não sejam oferecidos em outras disciplinas, sejam oferecidos através da disciplina de Ética Profissional.

Quanto aos egressos, estes citam como contribuição da disciplina: discussões que ela possibilita $(8,7 \%)$; definir conceitos de ética e moral (4,3\%); introduzir o exercício de uma postura ética (postura reflexiva/questionadora) $(4,3 \%)$; adequação das questões éticas abordadas na disciplina às encontradas na atuação $(4,3 \%)$.

Cada egresso foi convidado a atribuir a cada questão ética levantada (foram previstas no máximo 3 questões por egresso) "grau de contribuição da graduação e da disciplina de Ética Profissional para identificação e para produção de respostas". Encontramos os seguintes resultados, calculados por média aritmética por questão, considerando o número de participantes que respondeu cada questão: a maioria dos egressos considera a contribuição da graduação para identificação de questões éticas como muito satisfatória $(50,4 \%)$ ou satisfatória $(35,3 \%)$, nem satisfatória nem insatisfatória $(9,1 \%)$ num padrão decrescente até insatisfatória (5,3\%). O mesmo padrão se observa com relação ao seu auxílio na produção de respostas: $48,1 \% ; 39,9 \% ; 10,5 \% ; 1,4 \% ; 0 \%$, respectivamente. Nenhum participante a considerou muito insatisfatória.

Quanto à contribuição da disciplina de Ética Profissional, os egressos estão mais dispersos entre: muito satisfatória (34,5\%), satisfatória (39,3\%) e nem satisfatória, nem insatisfatória $(22,5 \%)$, insatisfatória $(2,2 \%)$, muito insatisfatória $(1,6 \%)$, sendo que apresentam maior concentração no item satisfatória. Quanto à produção de respostas foram obtidos os seguintes resultados, respectivamente: $28,9 \% ; 42,3 \% ; 25,6 \%, 0 \%$ e $3,1 \%$.

Ao contrário do que prevíamos, na percepção dos egressos, a graduação parece ter tido uma importância um pouco maior para a formação ética do que a disciplina de Ética Profissional isoladamente. Dessa forma, a graduação como um todo parece contribuir mais do que uma disciplina especifica para a formação ética.

Percebemos que não há diferenças contrastantes entre a contribuição para a identificação de questões éticas e para a produção de respostas, evidenciando que tanto a disciplina de Ética Profissional como a graduação contribui 
para essas ações.

Compreendemos então, que tanto a graduação como a disciplina de Ética Profissional tem contribuído para que as respostas às questões éticas encontradas por mais da metade dos egressos sejam por eles consideradas adequadas (52,2\%), e em menor proporção: $17,4 \%$ inadequadas e $13 \%$ adequadas, mas insuficientes. Apenas $8,7 \%$ não têm conseguido produzir nenhum tipo de resposta às questões e os demais não responderam à questão.

Alguns egressos valorizam a possibilidade que o Curso oferece de vivenciar diferentes situações práticas (estágios) $(8,7 \%)$. Da mesma forma, 1 docente coloca as "práticas e estágios supervisionados como estratégia essencial para promover questionamentos éticos":

(...) é sobretudo nas disciplinas de Práticas e Estágios Supervisionados que as questões éticas se colocam de forma efetiva para os alunos, quando se deparam com as pessoas atendidas, sua vida, sua realidade.

A questão trazida por esta docente está de acordo com o entendimento de que: "As experiências reais e diretas da vida coletiva e do processo de trabalho em saúde são os contextos em que o ensino e a aprendizagem da Ética se dão de maneira mais eficaz" (FERREIRA; RAMOs, 2006, p. 330).

Com relação às "articulações atuais entre a disciplina de Ética Profissional e as demais disciplinas do Curso", verificamos que 1 docente entende esta como base para a formação, e outras 5 que a articulação entre suas disciplinas e a de Ética Profissional ocorre através da complementaridade dos conteúdos éticos oferecidos.

Duas docentes manifestam a necessidade de construir espaços de intercâmbio e interlocução entre a disciplina de Ética Profissional e as outras disciplinas do Curso, incluindo os estágios e práticas supervisionadas. Isso se relaciona com o apontamento de 1 docente sobre sua dificuldade em avaliar as influências da disciplina de Ética Profissional, por esta ser oferecida em período em que a docente não está em contato direto com os alunos.

Alguns egressos também compreendem a necessidade de interlocução entre a disciplina de Ética e as demais disciplinas do Curso (13\%), sendo que 4,3\% aponta para a importância de vivenciar situações práticas em estágios simultaneamente à disciplina de Ética Profissional, $4,3 \%$ sugere que sejam destinadas aulas específicas para discussões de questões éticas a partir de vivências das mesmas pelos estudantes nos estágios, e 4,3\%, que as outras disciplinas consigam discutir as questões éticas e abordá-las principalmente nas práticas realizadas.

O momento em que a disciplina de Ética Profissional é oferecida sofre questionamentos das duas populações de estudo. Duas docentes refletem que:

A dificuldade é conseguir um ponto comum de articulação já que as disciplinas em questão são oferecidas em semestres diferentes (...).

(...) talvez fosse interessante (a disciplina de Ética Profissional) ser dada em diferentes momentos do Curso.

Uma docente questiona que:

(...) com apenas dois créditos, a disciplina corre riscos. Quando ministrei essa disciplina, avaliamos (eu e as turmas) que talvez fosse interessante ser dada em diferentes momentos do Curso.

Um egresso (4,3\%) também pontua a necessidade de alterar o período de oferecimento da disciplina e de que esta se relacione mais com a disciplina de Desempenho Profissional:

Considerando um planejamento ideal, sugere-se que a discussão sobre ética seja iniciada em momentos anteriores da formação profissional para que a discussão da disciplina possa relacionar-se mais com as atividades práticas de estágio e com a disciplina de Desempenho Profissional.

Outros apontamentos trazidos por egressos e docentes referem-se a necessidade de encontrar melhores "estratégias de ensino": 1 docente refere que busca sempre métodos mais eficazes de ensino nas disciplinas que ministra e $8,7 \%$ dos egressos sugerem o uso de discussões em grupo na disciplina de Ética Profissional, outros 8,7\% gostariam que esta utilizasse métodos mais dinâmicos.

Consideramos fundamental o estudo sobre métodos de ensino. Embora não tenha sido foco de nossa pesquisa, poderá ser alvo de próximos estudos.

O tema de "ética em pesquisa" foi trazido por um egresso $(4,3 \%)$, quando coloca como questão ética a necessidade de considerar na escolha do tema de pesquisa sua importância e relevância. As docentes não citaram especificamente este tema.

Foi apontado por $8,7 \%$ dos egressos que a "formação ética ocorre em outros espaços que não os da graduação", por exemplo, no cotidiano das práticas e em espaços permanentes de reflexão ética após a graduação.

Nenhuma das populações refere "questões éticas no âmbito do ensino de Terapia Ocupacional”. Esta esfera da atuação da Terapia Ocupacional possivelmente não tem sido foco dos docentes durante a formação, embora se registre expansão de Cursos de Terapia Ocupacional 
em nível nacional. Quanto aos egressos participantes da pesquisa, não exercem atividade neste âmbito.

\section{CONCLUSÃO}

As contribuições trazidas pelas duas populações estudadas relacionam-se, em geral, com princípios da bioética, pois envolvem a sensibilidade no cuidado, o zelo, a promoção da dignidade humana e de qualidade de vida.

A graduação em geral e a disciplina de Ética Profissional, particularmente, têm auxiliado a totalidade dos egressos a identificarem questões éticas em sua atuação e, tem contribuído para que metade destes produza respostas que consideram adequadas a estas questões.

Tanto docentes como egressos concordam que a graduação como um todo e a disciplina de Ética Profissional, em particular, contribuem para uma formação ética, entendida como reflexiva e crítica. E, que esta disciplina possibilita discussões de conteúdos éticos, assim como algumas disciplinas do Curso.

Ambas as populações concordam que os questio- namentos éticos são estimulados na disciplina de Ética Profissional e através das outras disciplinas, especialmente as práticas, entendidas como espaços estratégicos do ensino de ética.

Ambas as populações mostram um descontentamento com o formato atual do ensino de ética no Curso, concentrado em uma única disciplina, e apontam para que esta seja oferecida no decorrer do mesmo. Também, concordam que há falta de interlocução entre as disciplinas do Curso e a de Ética Profissional.

Temas não previstos no estudo, tais como aprimoramento dos métodos de ensino no Curso, e a importância de espaços de formação continuada foram apontados e podem ser alvo de próximos estudos.

Embora a questão de tomada de decisões éticas quando estas envolvem pessoas com autonomia reduzida seja essencial para o conhecimento dos Terapeutas Ocupacionais, nenhuma das populações participantes a cita explicitamente como questão ética.

Em geral, os apontamentos das participantes constituemse como material a ser considerado para aprimoramento da formação ética do Terapeuta Ocupacional na USP.

PEREIRA, M. A.; ALMEIDA, M. H. M. Dialogues between the teaching of ethics and ethical issues faced by Occupational Therapists. Rev. Ter. Ocup. Univ. São Paulo, v. 20, n. 2, p. 135-142, maio./ago. 2009.

\begin{abstract}
Human care professionals need formation that assists them in the identification and answering of ethical issues. The aim is to contribute for the improvement of ethics' teaching in Occupational Therapy at USP-SP. Exploratory and descriptive studies were conducted. Qualitativenatured information was obtained through an non-presential, open-ended questionnaire taken by this major's professors and graduate occupational therapists. The professors informed about ethical content in subjects under their responsibility, and the graduate occupational therapists talked about what ethical issues they have faced and what are the major's possible contributions to obtaining answers. A dialogue was established between the information obtained. The Professional Ethics discipline as well as some other subjects, specially practice disciplines, have contributed for an ethical formation. The survey's participants point to the importance of ethics' teaching throughout the formation and the creation of dialogue room. None have mentioned reduced autonomy as an ethical issue. The participants' pointers constitute as material to be considered for the improvement of ethical formation of the occupational therapist at USP.
\end{abstract}

KEY WORDS: Occupational therapy/ethics. Ethics, professional. Teaching/ethics.

\title{
REFERÊNCIAS
}

ALMEIDA, M. H. M.; CASTIGLIONI, M. C. O ensino da ética ao profissional de saúde na USP: a formação ética do Terapeuta Ocupacional. Rev. Ter. Ocup. Univ. São Paulo, v. 16/2, p. 68-74, 2005.
ALMEIDA, M. C.; COELHO, V. S.; SOMBINI, G. P.; PEREIRA, M. A.; BRAGA, C. P. A formação dos profissionais de saúde em transformação: questões para a Terapia Ocupacional. In: Anais do X CBTO: contextos, territórios e diversidades. Goiânia: Kelps/ 
editora da UCG, 2007.

BEAUCHAMP, T. L.; CHILDRESS, J. F. Principles of medical ethics. 2. ed. New York: Oxford University Press, 1985. p. 59105 .

BETTO, Frei. Adital: notícias da América Latina e Caribe; 2003. Disponível em: <http://www.adital.com.br/site/noticia. asp?lang=PT\&cod=7063> . Acesso em: 13 fev. 2009.

DINIZ, D.; GUILHEM, D. O que é bioética. São Paulo: Brasiliense; 2002. (Coleção: Primeiros Passos).

FERREIRA, H. M.; RAMOS, L. H. Diretrizes curriculares para o ensino da ética na graduação em enfermagem. Acta Paul. Enferm., v. 19, n. 3, p. 328-331, 2006.

FORTES, P. A. C. Ética e saúde: questões éticas, deontológicas e legais,tomada de decisões, autonomia e direitos do paciente, estudo de casos. São Paulo: EPU, 1998.

FRANCO, T. B. et. al. O acolhimento e os processos de trabalho em saúde: o caso de Betim. Cad. Saúde Pública, v. 15, n.2, p. 345-353, 1999.

GARRAFA, V. A dimensão da ética em saúde pública. São Paulo: Faculdade de Saúde Pública da USP, 1995. (Ad Saúde. Série Temática 4).

GUIMARÃES, M. C. S.; NOVAES, S. C. Autonomia reduzida e vulnerabilidade: liberdade de decisão, diferença e desigualdade. Rev. Bioética, v. 7, n. 1, 1999.

LIMA, E. M. F. A. Desejando a diferença: considerações acerca das relações entre os terapeutas ocupacionais e as populações atendidas por estes profissionais. Rev. Ter. Ocup. Univ. São Paulo, v. 14, n. 2, p. 64-71, 2003.

LIMA, E. M. F. A. A saúde mental nos caminhos da Terapia Ocupacional. Mundo Saúde, v. 30, n. 1, p. 117-122, 2006.

PESSINI, L.; BARCHIFONTAINE, C. de P. (Orgs.). Bioética e longevidade humana. São Paulo: Centro Universitário São Camilo: Edições Loyola, 2006.

SARACENO, B. Libertando identidades: da reabilitação psicossocial à cidadania possível: a reabilitação como cidadania. Rio de Janeiro: Instituto Franco Basaglia: TeCorá, 1999.

SEGRE, M.; COHEN, C. Bioética. 2. ed. São Paulo: EDUSP, 1999.

VALLS, A. L. M. O que é ética. São Paulo: Brasiliense; 2006.

VASQUEZ, A. S. Ética. Rio de Janeiro: Civilização Brasileira, 2002

ZOBOLI, E. L. C. P. Bioética do cuidar: a ênfase na dimensão relacional. São Paulo: Rev. Estima, v. 1, n. 1, p. 38-40, 2003. 